\title{
Long-Term Use of Dual Antiplatelet Therapy For The Secondary Prevention of Atherothrombotic Events: Meta-analysis of Randomized Controlled Trials
}

\author{
Zaher Fanari, M.D. ${ }^{1}$, Amratash Malodiya, M.B.B.S. ${ }^{2}$, Sandra A. Weiss, M.D ${ }^{2}$, Sumaya \\ Hammami, M.D., M.P.H. ${ }^{1}$, Paul Kolm, Ph.D. ${ }^{3}$, and William S. Weintraub, M.D. ${ }^{2,3}$ \\ ${ }^{1}$ University of Kansas School of Medicine, Kansas City, KS \\ ${ }^{2}$ Section of Cardiology, Christiana Care Health System, Newark, DE \\ ${ }^{3}$ Value Institute, Christiana Care Health System, Newark, DE
}

\section{Abstract}

Background-The potential benefit of long-term dual antiplatelet therapy (DAPT) for secondary prevention of atherothrombotic events is unclear. Data from different randomized controlled trials (RCT) using different agents in different subgroups showed inconsistent results.

\begin{abstract}
Methods-We performed a systematic review and meta-analysis from RCTs that tested different prolonged durations of DAPT for secondary prevention. Long term DAPT arm was defined as those receiving DAPT for more than 12 months. Long-term aspirin arm was defined as those receiving either Aspirin alone long term or DAPT for less than 12 months.
\end{abstract}

\begin{abstract}
Results-The use of long term DAPT was associated with a significant decrease in composite of death, myocardial infarction (MI) and stroke (6.08\% vs. 6.71\%; Odd Ratio OR= 0.86 [0.78-0.94]; $\mathrm{P}=0.001$ ). This reduction of death, $\mathrm{MI}$ and stroke was mainly noticed in patients with prior MI or stroke, but not with PAD or multiple risk factors. The reduction was seen with post PCI patients with prasugrel and only in those with prior MI with clopidogrel and ticagrelor. Long-term use of DAPT was associated with significant increase in major bleeding $(1.47 \%$ vs. $0.88 \%$; OR $=1.65$ [1.23 - 2.21]; $\mathrm{P}=0.001)$.

Conclusion-Long-term use of DAPT for secondary prevention is associated with lower risk of death, MI and stroke beneficial especially in patients with prior MI and stroke, but it is associated with increased risk of bleeding. Prolonging DAPT requires careful assessment of the trade-off between ischemic and bleeding complications and should probably reserved for patients with higher risk for atherothrombotic events.
\end{abstract}

\footnotetext{
Corresponding Author: Zaher Fanari, M.D., University of Kansas School of Medicine, Kansas City, KS., 3901 Rainbow Boulevard, Kansas City, Kansas 66160. Tel: +1 (314) 808-1610 Fax: +1 (913) 588-6010 zfanari@ gmail.com.

Disclosure Statement:

None of authors have any disclosures.

Conflict of interest:

Drs. Fanari, Malodiya, Weiss, Hammami and Kolm report no conflicts of interest.
} 


\section{Keywords}

Dual antiplatelet therapy; Secondary Prevention; Atherothrombotic; P2Y12 inhibitors

\section{Introduction}

Atherosclerotic vascular disease including coronary artery disease, cerebrovascular disease, and peripheral arterial disease are the leading cause of death and disability in the world. ${ }^{(1)}$ Platelets activation plays a key rule in the pathobiology of thrombotic ischemic events. (2) Aspirin monotherapy reduces the risk of ischemic events both among patients who present with an acute coronary syndrome and in secondary prevention for patients with atherosclerotic vascular disease. (3) The addition of a P2Y12 receptor antagonist to aspirin has been shown to reduce further the risk of ischemic events in patients with symptomatic atherosclerotic vascular disease. (4)

Multiple Studies compared long-term dual antiplatelet therapy (DAPT) to ASA or short DAPT. Findings of these studies assessing the effect of extended duration dual antiplatelet therapy varied. As while the Clopidogrel and Aspirin versus Aspirin Alone for the Prevention of Atherothrombotic Events (CHARISMA) trial showed reduction in no difference in both cardiac and non cardiac death, (4) similarly other studies [ITALIC (Is There A LIfe for DES after discontinuation of Clopidogrel), PRODIGY (PROlonging Dual antiplatelet treatment after Grading stent-induced Intimal hyperplasia studY) and DES LATE (optimal duration of clopidogrel therapy with DES to reduce Late coronary Arterial Thrombotic Event)] showed similar trends in regards of all cause and cardiac death. (5-7) However the Dual Antiplatelet Therapy Study (DAPT Study) showed no difference in cardiac death and higher incidence on non-cardiac death.(8) The results of DAPT were not consistent with those of PEGASUS-TIMI 54 trial (the Patients With Prior Heart Attack Using Ticagrelor Compared to Placebo on a Background of Aspirin-Thrombolysis in Myocardial Infarction) that showed a lower incidence of cardiac death with no difference in death from other causes. (9) Using meta-analysis to pool data from multiple RCTs provides a more precise assessment of the effects of treatment, and also increases the number of patients within clinical subgroups of interest, often providing adequate statistical power to evaluate outcomes in these subgroups. ${ }^{(10)}$ While multiple meta-analyses were published comparing different durations of dual antiplatelets, all these meta-analysis included RCT where both arms have no long term DAPT beyond 12 months after percutaneous intervention or MI and some of them only looked at patients after Drug-Eluting Stent (DES) implantation. (11-14) Therefore none of these meta-analyses is able to address the issue of using long term DAPT in the secondary prevention of death, Myocardial Infarction (MI) and/or stroke in patients with atherosclerotic diseases.

Our current meta-analysis compares the rule of long-term DAPT vs. long term ASA in the secondary prevention of atherothrombotic events in patients with atherosclerotic diseases. 


\section{Methods}

Relevant studies were identified through electronic searches of MEDLINE and the Cochrane Central Register of Controlled Trials databases from 01/01/1997 to 05/10/2015. The start date was defined as 01/01/1997 as the FDA approved the use of first P2Y12 inhibitor "clopidogrel" in 1997.

The search strategy used the terms "dual antiplatelet therapy," "DAPT", "Long-Term" "prevention", "coronary artery disease" or "peripheral vascular disease," "stroke." "clopidogrel", "Plavix", "prasugrel”, "Effient", "ticagrelor", "Brilinta”, "thienopyridine”, "DAPT", "death", "mortality", "survival", "randomized controlled trial", "random", "random allocation", "double-blind", and "single-blind". Searches were restricted to trials of human participants with full text published in English. In addition, we searched bibliographies of relevant studies, reviews, editorials, letters, and meeting abstracts. The analysis was restricted to include only prospective RCTs or pre-specified sub-analyses from RCTs that included an arm with randomized patients to long-term DAPT; and reported both safety and efficacy outcomes. All included studies reported each of the following efficacy outcomes: composite of death/MI/Stroke, All cause death, cardiac death, MI, stroke as well as safety data including a minimum of minor or moderate bleeding and major bleeding. Also each of the included study have a long term arm of DAPT extends beyond 12 month after MI or PCI if the patient have coronary artery disease (CAD).

The quality of the identified studies was assessed with respect to control for confounders, measurement of exposure, completeness of follow-up, and blinding. We followed a coring system based on a checklist derived from recommended criteria recommended by the QUOROM (The Quality of Reporting of Meta-analyses) and PRISMA (Preferred Reporting Items for Systematic Reviews and Meta-Analyses) guidelines to assess the quality of the trials used in this meta-analysis. $(15,16)$

Three reviewers (ZF, AM and SM) independently extracted data from the list of included studies. Extracted data included authorship, study period, publication year, study design, study region, baseline characteristics of patients, sample size, clinical events, and duration of follow-up. The following outcomes were extracted: composite of death/ MI and stroke (primary end point), all-cause death, cardiac death, MI and stroke [cerebrovascular accident (CVA)] for efficacy outcomes and minor/moderate and major bleeding for safety outcomes.

A random effects model meta-analysis following the DerSimonian-Laird method was used to determine relative risks for the ASA alone and long DAPT groups for each endpoint. ${ }^{(17)}$ This method treats study affiliation as a random effect and considers both the within-study variance and the between-study variance. Heterogeneity (inconsistency of results among studies) was assessed using the DerSimonian-Laird I2 statistic, which calculates the proportion of between-study variability that cannot be attributed to sampling variation. ${ }^{(18)}$ All meta-analyses were conducted with $\mathrm{R}$ statistical software for Windows with the package meta (R Foundation for Statistical Computing, Vienna, Austria). 


\section{Results}

Our systematic literature search identified 2456 articles, of which 6 met the inclusion criteria for this analysis (Figure 1). These 6 RCT included a total of 55563 patients. (4-9) The populations included in these trials were distributed as follows: one trial of patients at high risk of atherothrombotic events, (4) and five trials of patients with coronary artery disease after percutaneous coronary intervention and or acute coronary syndrome. (5-9) Dual antiplatelet therapy in all trials consisted of aspirin and P2Y12 inhibitor. (4-9) Four trials used clopidogrel exclusively as the P2Y12 inhibitor used, (4-7) one trial included clopidogrel and prasugrel, (8) while one trial used ticagrelor as the P2Y12 inhibitor. (9) Supplemental table-1 shows characteristics of each of these RCT, while supplemental table-2 shows the patients characteristics of the meta-analysis cohort.

\section{Efficacy}

The use of long term DAPT was associated with a significant decrease in the primary outcome consist of a composite of death, MI and stroke (6.08\% vs. $6.71 \%$; Odd Ratio OR= 0.86 [0.78-0.94]; $\mathrm{P}=0.001$; Figure-2). The use of long term DAPT was not associated with any differences in all-cause death (4.13\% vs. $4.05 \%$; $\mathrm{OR}=1.02$ [0.85-1.22]; $\mathrm{P}=0.83)$, cardiac death $(2.26 \%$ vs. $2.27 \%$; $\mathrm{OR}=0.96$ [0.85-1.08]; $\mathrm{P}=0.46)$ or stroke $(1.35 \%$ vs. $1.61 \% ; \mathrm{OR}=0.85$ [0.71-1.02]; $\mathrm{p}=0.07)$. However the use of long term DAPT was associated with a significant decrease in the incidence of MI $(2.77 \%$ vs. $3.16 \%$; OR $=0.75$ [0.58-0.96]; $\mathrm{P}=0.03$ ). Figure-3 shows the impact of the long term DAPT use on the individual efficacy outcomes.

The reduction in the composite of death, MI and stroke was not consistent in all subgroups. While DAPT use was effective in patients with prior MI (6.32\% vs. 7.28\%; OR=0.86 [0.79$0.94]$; $\mathrm{P}<0.001)$ and prior stroke ( $8.40 \%$ vs. $10.70 \%$; $\mathrm{OR}=0.78$ [0.62-0.98]; $\mathrm{P}=0.03)$, the reduction in the composite of death, $\mathrm{MI}$ and stroke was not significant in patients with PAD (7.6\% vs. 8.9\%; $\mathrm{OR}=0.84$ [0.65-1.08]; $\mathrm{P}=0.18)$, non-ACS PCI patients ( $4.66 \%$ vs. $5.03 \%$; $\mathrm{OR}=0.87$ [0.80-0.94]; $\mathrm{P}=0.38$ ), or in patients with multiple atherothrombotic risk factors (5.60\% vs. $4.80 \%$; $\mathrm{OR}=1.05$ [0.77-1.43]; $\mathrm{P}=0.74)$. While the reduction in the composite of death, MI and stroke was non significant with clopidogrel in non ACS PCI patients (4.66\% vs. 5.03\%; $\mathrm{OR}=0.87$ [0.80-0.94]; $\mathrm{P}=0.38)$, this was not the case in those with (4.89\% vs. $6.28 \% \mathrm{OR}=0.77$ [0.66-0.9]; $\mathrm{P}<0.01)$. The reduction in death, MI and stroke was prominent with prasugrel $(3.10 \%$ vs. $5.90 \%$; $\mathrm{OR}=0.53$ [0.37-0.74]; $\mathrm{P}<0.001)$ and ticagrelor $(6.95 \%$ vs. $5.72 \% ; \mathrm{OR}=0.84$ [0.75-0.93]; $\mathrm{P}=0.001)$. Table-1 summarizes the impact of the long-term use of different $\mathrm{P} 2 \mathrm{Y} 12$ agents on the primary endpoint.

\section{Safety}

The use of long term DAPT was associated with a significant rise in both minor/moderate bleeding ( $1.31 \%$ vs. $0.81 \%$; $\mathrm{OR}=1.90$ [1.38 - 2.62]; $\mathrm{P}=0.001)$ and major bleeding $(1.47 \%$ vs. $0.88 \% ; \mathrm{OR}=1.65[1.23-2.21] ; \mathrm{P}=0.001)$. Figure-4 shows the impact of the long term DAPT use on minor/moderate and major bleeding. 


\section{Discussion}

This meta-analysis of RCT comparing long term DAPT use to long term ASA use for the secondary prevention in patients with known atherothrombotic disease. The use of long term DAPT was associated with reduction in the primary efficacy endpoint of death/MI and stroke. This reduction was mainly driven by reduction in the incidence of MI with no significant impact on the incidence of all death, cardiac death and stroke. The reduction was mainly seen in patients with CAD or prior stroke, but not in those with symptomatic PAD or those with multiple atherothrombotic risk factors. While the reduction was noticed with the use of any P2Y12 inhibitor, the reduction was minimal with clopidogrel, but more pronounced with both prasugrel and ticagrelor. However this reduction in atherothrombotic events with the long-term use of DAPT is also associated with significant increase in the risk of both minor/moderate and major bleeding.

The use of long term DAPT for secondary prevention of atherothrombotic events was assessed originally in CHARISMA study, adding clopidogrel to ASA was associated with a non-significant trend in reducing death, MI and stroke. This trend was more significant in patients with prior MI or stroke, but not in those with PAD or multiple atherothrombotic risk factors. $(4,19,20)$ After CHARISMA, three RCTs (ITALIC, PRODIGY and DES LATE) assessing the role of long term DAPT (ASA and Clopidogrel) in patients with CAD after placement of drug eluting stents (DES) did not show any significant reduction in the death, MI and stroke. (5-7) However DAPT trial that compared long term DAPT in patients with CAD after placement of drug eluting stents (66\% clopidogrel and $34 \%$ prasugrel) similarly in patients with CAD after placement of drug eluting stents showed the use of DAPT was associated with very significant reduction in death, MI and stroke. (8) This was followed by PEGASUS-TIMI 54 trial that assessed the benefit of long term DAPT (ticagrelor) in patients with prior MI and showed similarly to DAPT trial a very significant reduction in death, MI and stroke. (9)

In assessing each of the individual outcomes in the RCT showed some heterogeneity in the outcomes among different trials. As while there was no significant difference in the incidence of either all cause death or cardiac death in CHARISMA, ITALIC, PROGIDY and PEGASUS-TIMI 54 between both strategies, $(4-6,9)$ there was a non-significant trend for higher all cause death and cardiac death in DES LATE trial. (7) In DAPT trial, while there was no significant difference in cardiac death, there was a higher all cause mortality driven by an increase in non-cardiac death. (8) However the increase in all cause death in this trial was mainly driven by an increase in cancer related death with no significant in bleeding related death. (8) As for the reduction in MI, while there was no difference noticed in CHARISMA, ITALIC, PROGIDY and DES LATE trials, (4-7) there was very significant reduction in the incidence of MI in both DAPT and PEGASUS-TIMI 54 trials. $(8,9)$ Similarly, the reduction in stroke varies in different studies with significant reduction noticed only in 2 trials (CHARISMA and PEGASUS-TIMI 54). $(4,9)$

Looking to different subgroups of patient at risk. CHARISMA trial established that most of the benefits of long DAPT therapy are patients with prior MI or stroke, but not in those with PAD or multiple atherothrombotic risk factors. (4) As for patients with CAD, while three 
RCTs (ITALIC, PROGIDY and DES LATE) did not show a significant reduction in the incidence of death, MI and stroke, (5-7) this finding was challenged by the finding of DAPT trial where long term DAPT was associated with significant reduction of death, MI and stroke. (8) However looking a closer look to the subgroups of DAPT trial shows that the main benefits were witnessed in patients with ACS in comparison to non-ACS patients. (21) These results are consistent with the benefit in patients with prior MI established originally in CHARISMA trial and reconfirmed in PEGASUS-TIMI 54. $(4,9)$

The choice of the antiplatelets used may have an impact on the outcomes of log term ACS. As the use of clopidogrel in addition to ASA was not associated with a reduction in death, MI and stroke in ITALIC, PROGIDY and DES LATE as well as the all cohort of CHARISMA trial. (4-7) Similarly, the clopidogrel subgroup in DAPT trial had a nonsignificant reduction in death, MI and stroke. However, it should be noticed that clopidogrel use specifically in patients with in patients with prior MI or stroke was significant in CHARISMA. The data on the clopidogrel subgroup in patients with ACS suggests that the use clopidogrel in this subgroup was beneficial. (21) As for the newer P2Y12 agents, the use of prasugrel in the long term DAPT arm in the DAPT trial was associated with very significant reduction in the incidence of death, MI and Stroke. $(8,21)$ Similarly, the use of ticagrelor in the PEGASUS-TIMI 54 was associated with significant reduction in the incidence of death, MI and Stroke in both ticagrelor doses. (9)

Most of studies showed increase risk of bleeding with long-term DAPT. The reporting of bleeding events varied extensively between the different trials, however it seems that although there was significant increase in moderate and severe bleeding, there was no increase risk in fatal bleeding with long term DAPT. (4-9)

Multiple meta-analyses were performed comparing different duration of DAPT in patients after the placement of DES. (11-14) All these meta-analysis were designed to test for the safety of early discontinuation of DAPT from the standpoint of stent thrombosis and bleeding. The long-term arms of all these meta-analyses were combined 12 months use of DAPT. Furthermore, although some of these meta-analyses reported a comparison of cardiac death or MI, none of them reported data on the impact on all thrombotic events including the composite of death, MI and stroke or the individual outcomes of death, cardiac death, MI or strokes. (11-14) Therefore none of these meta-analyses qualify to assess the impact for secondary prevention of antithrombotic beyond 12 months in patients with CAD.

Our meta-analysis provide the first meta-analysis addressing the efficacy and safety of long term use of DAPT for the secondary prevention of atherothrombotic events in different clinical subgroups and comparing different P2Y12 agents. However there are several limitations to our meta-analysis. First as with any other meta-analysis the results are affected by variation in study design, endpoint definitions, endpoint reporting and possible publication bias. Second, Although we were able to report efficacy outcomes in different subgroups, the different design and reporting by different trials limited our ability to provide the individual outcomes of death, cardiac death, MI or strokes or more defined bleeding outcomes for each of the clinical subgroups. Third, we used published event rates for each trial as opposed to individual patient data. Access to individual patient data would have 
enabled use to report a more detailed subgroup analyses and perform a propensity analyses to account for differences in risk to minimize potential bias. Fourth, the DES used in the CAD patients in these trials varies extensively and between first and second generation DES and we were unable to study the impact of that on atherothrombotic events. Fifth, some of the patients in the aspirin arm received a short term DAPT (Patients from ITALIC and PRODIGY trials). Sixth, the duration of the long term DAPT varied extensively among the different trials. Finally, the data on the newer P2Y12 inhibitors are limited to patients with CAD with no data on their impacts in patients with previous strokes or PAD.

\section{Conclusion}

The use of long term DAPT is beneficial in reducing death/MI and stroke in patients with prior MI and stroke. This benefit is mainly driven by reduction in the risk of MI. However long term DAPT use is associated with significant increase in moderate and severe bleeding.

\section{Supplementary Material}

Refer to Web version on PubMed Central for supplementary material.

\section{Acknowledgments}

Funding:

Funded in part by an Institutional Development Award (IDeA) from the National Institute of General Medical Sciences of the National Institutes of Health under grant number U54-GM104941 (PI: Binder-Macleod).

Dr. Weintraub is a consultant for AstraZeneca, Lilly and Sanofi.

\section{Abbreviations}

CHARISMA

ITALIC

PRODIGY

DES LATE

DAPT Study

PEGASUS-TIMI 54
Clopidogrel and Aspirin versus Aspirin Alone for the Prevention of Atherothrombotic Events

Is There A LIfe for DES after discontinuation of Clopidogrel

PROlonging Dual antiplatelet treatment after Grading stent-induced Intimal hyperplasia studY

optimal duration of clopidogrel therapy with DES to reduce Late coronary Arterial Thrombotic Event

the Dual Antiplatelet Therapy Study

the Patients With Prior Heart Attack Using Ticagrelor Compared to Placebo on a Background of AspirinThrombolysis in Myocardial Infarction

ASA Aspirin

DAPT Dual antiplatelets therapy 
MI

EES

DES

BMS
Mypcardial Infarction

Everolimus-Eluting Stents

Drug Eluting Stents

Bare Metal Stents

\section{References}

1. Lopez AD, Murray CC. The global burden of disease, 1990-2020. Nat Med. 1998 Nov; 4(11):12411243. PubMed PMID: 9809543. [PubMed: 9809543]

2. Kapoor JR. Platelet activation and atherothrombosis. N Engl J Med. 2008 Apr 10; 358(15):16381639. PubMed PMID: 18403776. [PubMed: 18403776]

3. Baigent C, Blackwell L, Collins R, Emberson J, Godwin J, et al. Antithrombotic Trialists C. Aspirin in the primary and secondary prevention of vascular disease: collaborative meta-analysis of individual participant data from randomised trials. Lancet. 2009 May 30; 373(9678):1849-1860. PubMed PMID: 19482214. Pubmed Central PMCID: 2715005. [PubMed: 19482214]

4. Bhatt DL, Fox KA, Hacke W, Berger PB, Black HR, Boden WE, et al. Clopidogrel and aspirin versus aspirin alone for the prevention of atherothrombotic events. N Engl J Med. 2006 Apr 20; 354(16):1706-1717. PubMed PMID: 16531616. [PubMed: 16531616]

5. Gilard M, Barragan P, Noryani AA, Noor HA, Majwal T, Hovasse T, et al. 6-versus 24-month dual antiplatelet therapy after implantation of drug-eluting stents in patients nonresistant to aspirin: the randomized, multicenter ITALIC trial. J Am Coll Cardiol. 2015 Mar 3; 65(8):777-786. PubMed PMID: 25461690. [PubMed: 25461690]

6. Valgimigli M, Campo G, Monti M, Vranckx P, Percoco G, Tumscitz C, et al. Short-versus long-term duration of dual-antiplatelet therapy after coronary stenting: a randomized multicenter trial. Circulation. 2012 Apr 24; 125(16):2015-2026. PubMed PMID: 22438530. [PubMed: 22438530]

7. Lee CW, Ahn JM, Park DW, Kang SJ, Lee SW, Kim YH, et al. Optimal duration of dual antiplatelet therapy after drug-eluting stent implantation: a randomized, controlled trial. Circulation. 2014 Jan 21; 129(3):304-312. PubMed PMID: 24097439. [PubMed: 24097439]

8. Mauri L, Kereiakes DJ, Yeh RW, Driscoll-Shempp P, Cutlip DE, Steg PG, et al. Twelve or 30 months of dual antiplatelet therapy after drug-eluting stents. N Engl J Med. 2014 Dec 4; 371(23): 2155-2166. PubMed PMID: 25399658. [PubMed: 25399658]

9. Bonaca MP, Bhatt DL, Cohen M, Steg PG, Storey RF, Jensen EC, et al. Long-term use of ticagrelor in patients with prior myocardial infarction. N Engl J Med. 2015 May 7; 372(19):1791-1800. PubMed PMID: 25773268. [PubMed: 25773268]

10. Hlatky MA, Boothroyd DB, Bravata DM, Boersma E, Booth J, Brooks MM, et al. Coronary artery bypass surgery compared with percutaneous coronary interventions for multivessel disease: a collaborative analysis of individual patient data from ten randomised trials. Lancet. 2009 Apr 10; 373(9670):1190-1197. [PubMed: 19303634]

11. Giustino G, Baber U, Sartori S, Mehran R, Mastoris I, Kini AS, et al. Duration of Dual Antiplatelet Therapy After Drug-Eluting Stent Implantation: A Systematic Review and Meta-Analysis of Randomized Controlled Trials. J Am Coll Cardiol. 2015 Apr 7; 65(13):1298-1310. PubMed PMID: 25681754. [PubMed: 25681754]

12. Stefanini GG, Siontis GC, Cao D, Heg D, Juni P, Windecker S. Short versus long duration of DAPT after DES implantation: a meta-analysis. J Am Coll Cardiol. 2014 Sep 2; 64(9):953-954. PubMed PMID: 25169183. [PubMed: 25169183]

13. Elmariah S, Mauri L, Doros G, Galper BZ, O'Neill KE, Steg PG, et al. Extended duration dual antiplatelet therapy and mortality: a systematic review and meta-analysis. Lancet. 2015 Feb 28; 385(9970):792-798. PubMed PMID: 25467565. Pubmed Central PMCID: 4386690. [PubMed: 25467565]

14. El-Hayek G, Messerli F, Bangalore S, Hong MK, Herzog E, Benjo A, et al. Meta-analysis of randomized clinical trials comparing short-term versus long-term dual antiplatelet therapy 
following drug-eluting stents. Am J Cardiol. 2014 Jul 15; 114(2):236-242. PubMed PMID: 24856318. [PubMed: 24856318]

15. Moher D, Cook DJ, Eastwood S, Olkin I, Rennie D, Stroup DF. Improving the quality of reports of meta-analyses of randomised controlled trials: the QUOROM statement. Quality of Reporting of Meta-analyses. Lancet. 1999 Nov 27; 354(9193):1896-1900. PubMed PMID: 10584742.

[PubMed: 10584742]

16. Moher D, Liberati A, Tetzlaff J, Altman DG. Group P. Preferred reporting items for systematic reviews and meta-analyses: the PRISMA statement. Ann Intern Med. 2009 Aug 18; 151(4):264 269. W64. PubMed PMID: 19622511. [PubMed: 19622511]

17. DerSimonian R, Laird N. Meta-analysis in clinical trials. Control Clin Trials. 1986 Sep; 7(3):177188. PubMed PMID: 3802833. [PubMed: 3802833]

18. Higgins JP, Thompson SG. Quantifying heterogeneity in a meta-analysis. Stat Med. 2002 Jun 15; 21(11):1539-1558. PubMed PMID: 12111919. [PubMed: 12111919]

19. Bhatt DL, Flather MD, Hacke W, Berger PB, Black HR, Boden WE, et al. Patients with prior myocardial infarction, stroke, or symptomatic peripheral arterial disease in the CHARISMA trial. J Am Coll Cardiol. 2007 May 15; 49(19):1982-1988. PubMed PMID: 17498584. [PubMed: 17498584]

20. Cacoub PP, Bhatt DL, Steg PG, Topol EJ, Creager MA. Investigators C. Patients with peripheral arterial disease in the CHARISMA trial. Eur Heart J. 2009 Jan; 30(2):192-201. PubMed PMID: 19136484. [PubMed: 19136484]

21. Yeh RW, Kereiakes DJ, Steg PG, Windecker S, Rinaldi MJ, Gershlick AH, et al. Benefits and Risks of Extended Duration Dual Antiplatelet Therapy after PCI in Patients With and Without Acute Myocardial Infarction. J Am Coll Cardiol. 2015 Mar 5. PubMed PMID: 25787199. 


2460 articles identified
through systematic
review of scientific literature
2414 excluded: Irrelevant, duplicate, non-RCT, subgroup/ secondary analysis, short follow-up
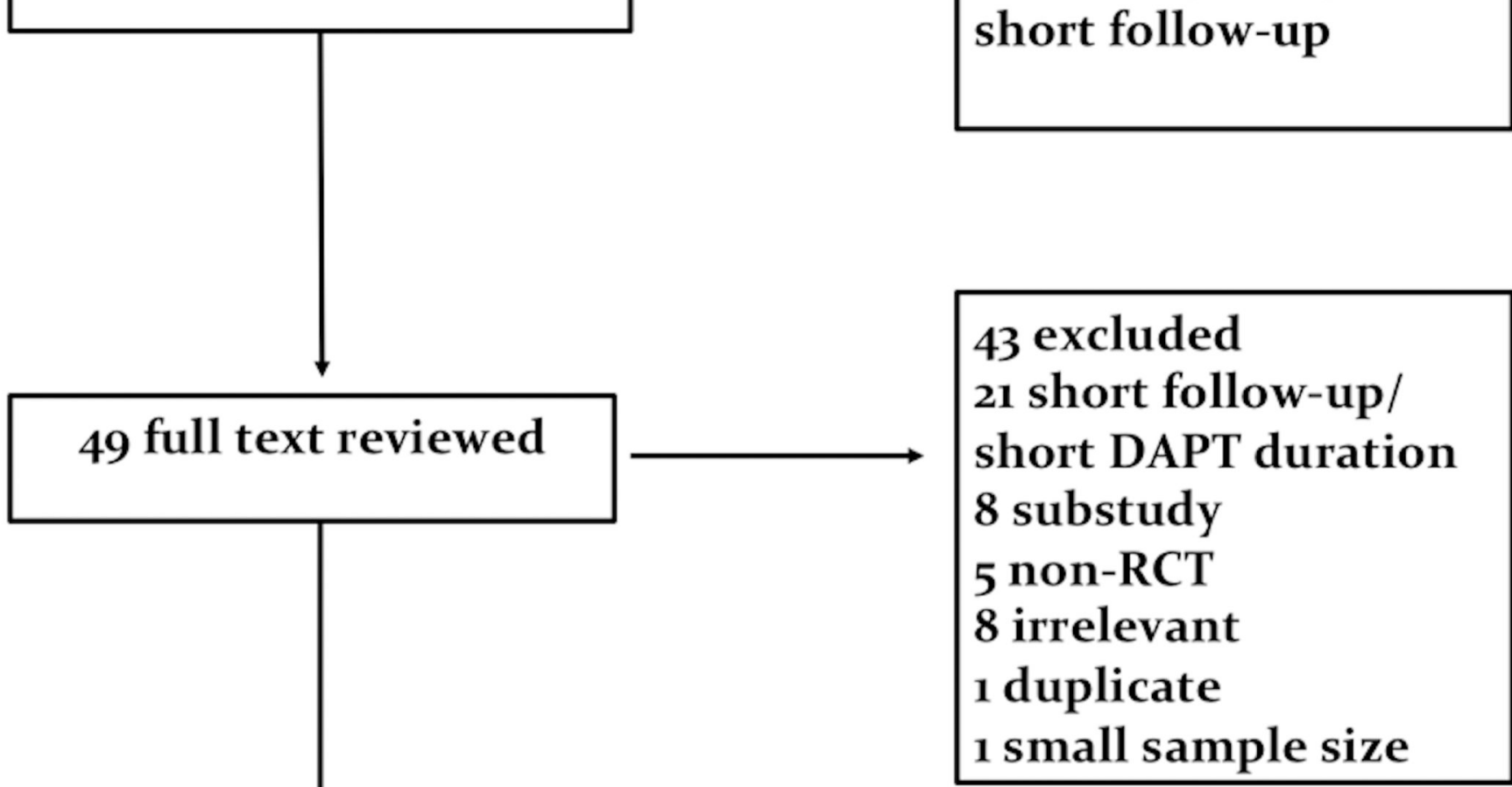

6 RCT met inclusion Criteria

Figure-1.

Flow Diagram of the Study Selection Process. 


\section{DAPT vs. ASA alone: Death/MI/Stroke $(\mathrm{p}=$ o.oor $)$}

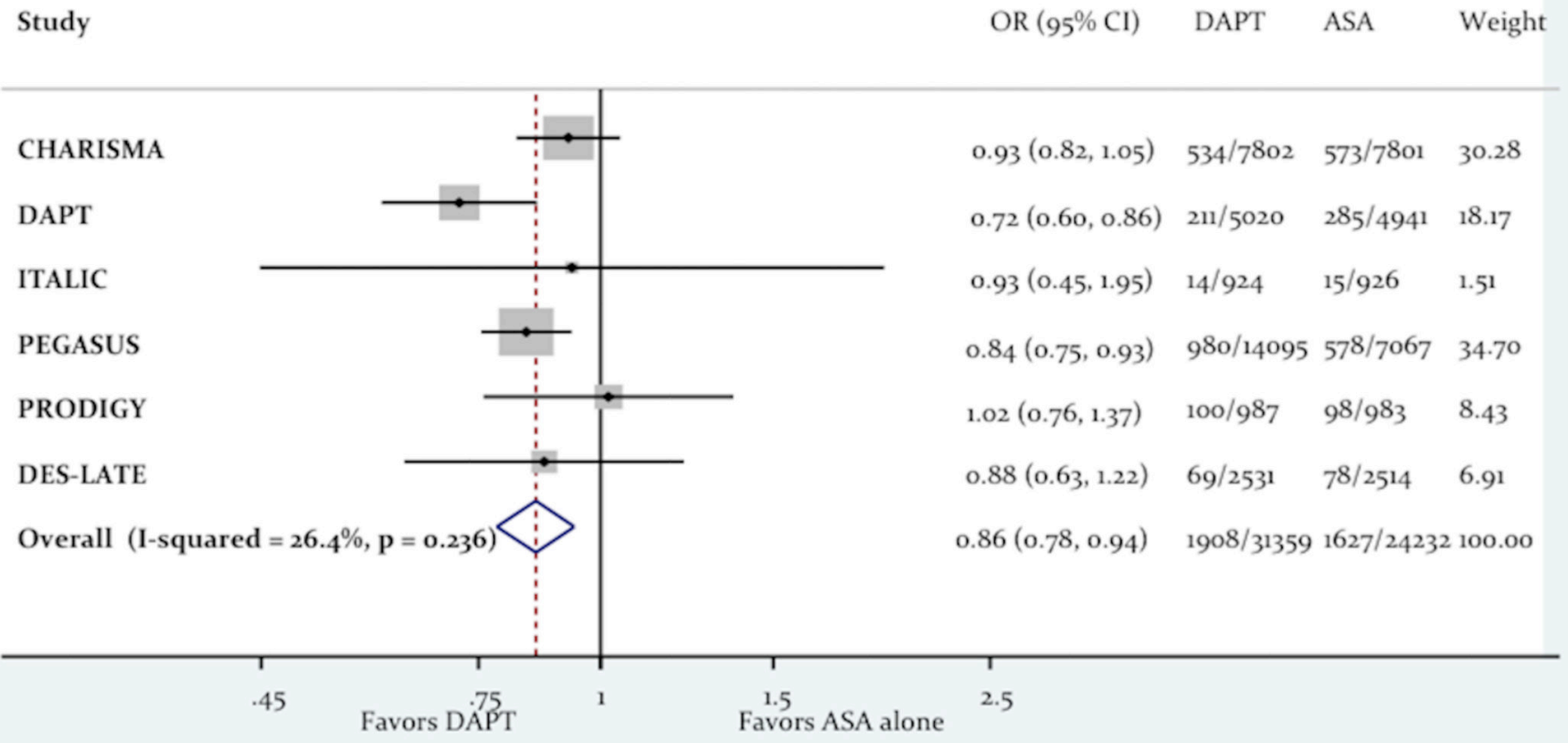

Figure-2.

The Impact Of Long Term DAPT On The Composite Of Death, MI And Stroke. 


\section{DAPT vs. ASA alone: All-cause death $(\mathrm{p}=0.829)$}

Study

OR $(95 \% \mathrm{CI})$ DAPT ASA Weight

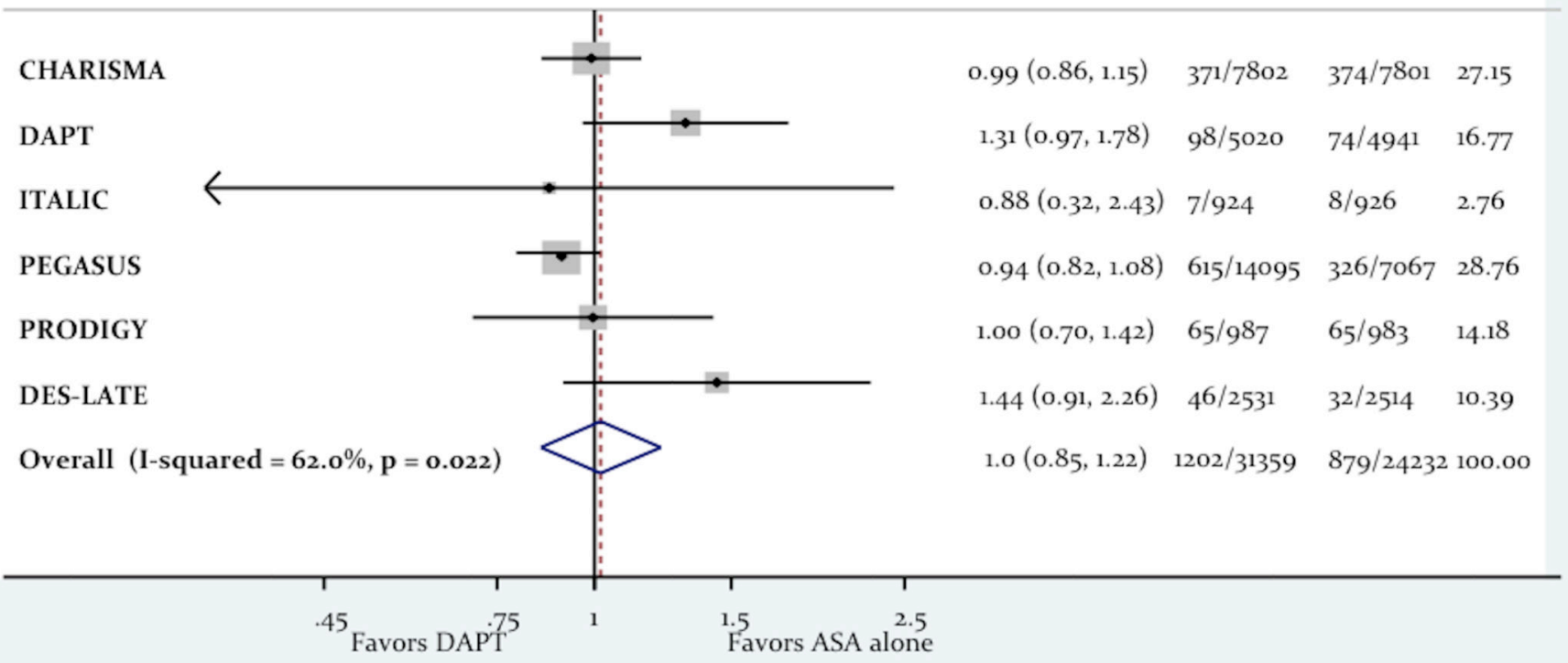

\section{DAPT vs. ASA alone: Cardiac Death $(p=0.462)$}

Study

OR $(95 \% \mathrm{CI}) \quad$ DAPT ASA Weight

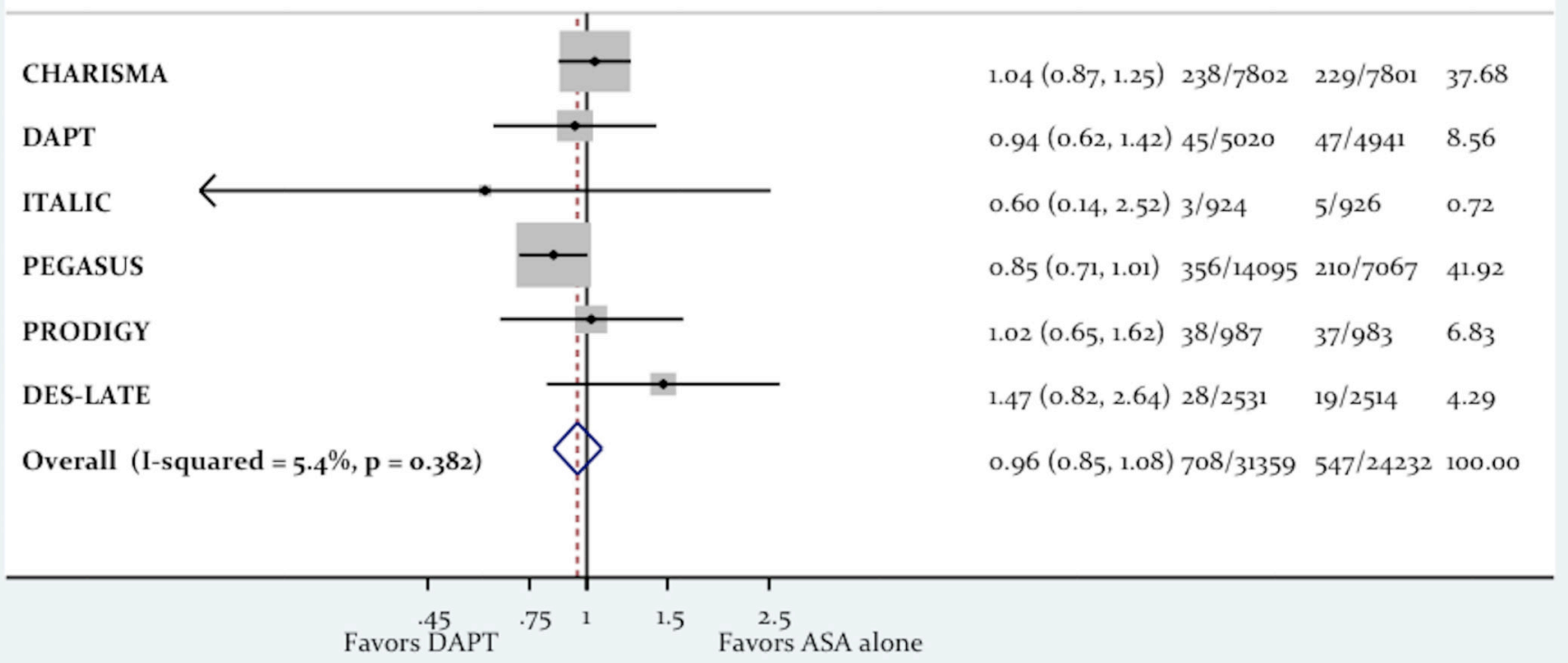

Cardiovasc Revasc Med. Author manuscript; available in PMC 2018 January 01. 


\section{DAPT vs. ASA alone: $\mathrm{MI}(\mathrm{p}=\mathbf{0 . 0 2 5})$}

Study

OR $(95 \% \mathrm{CI}) \quad$ DAPT $\quad$ ASA Weight

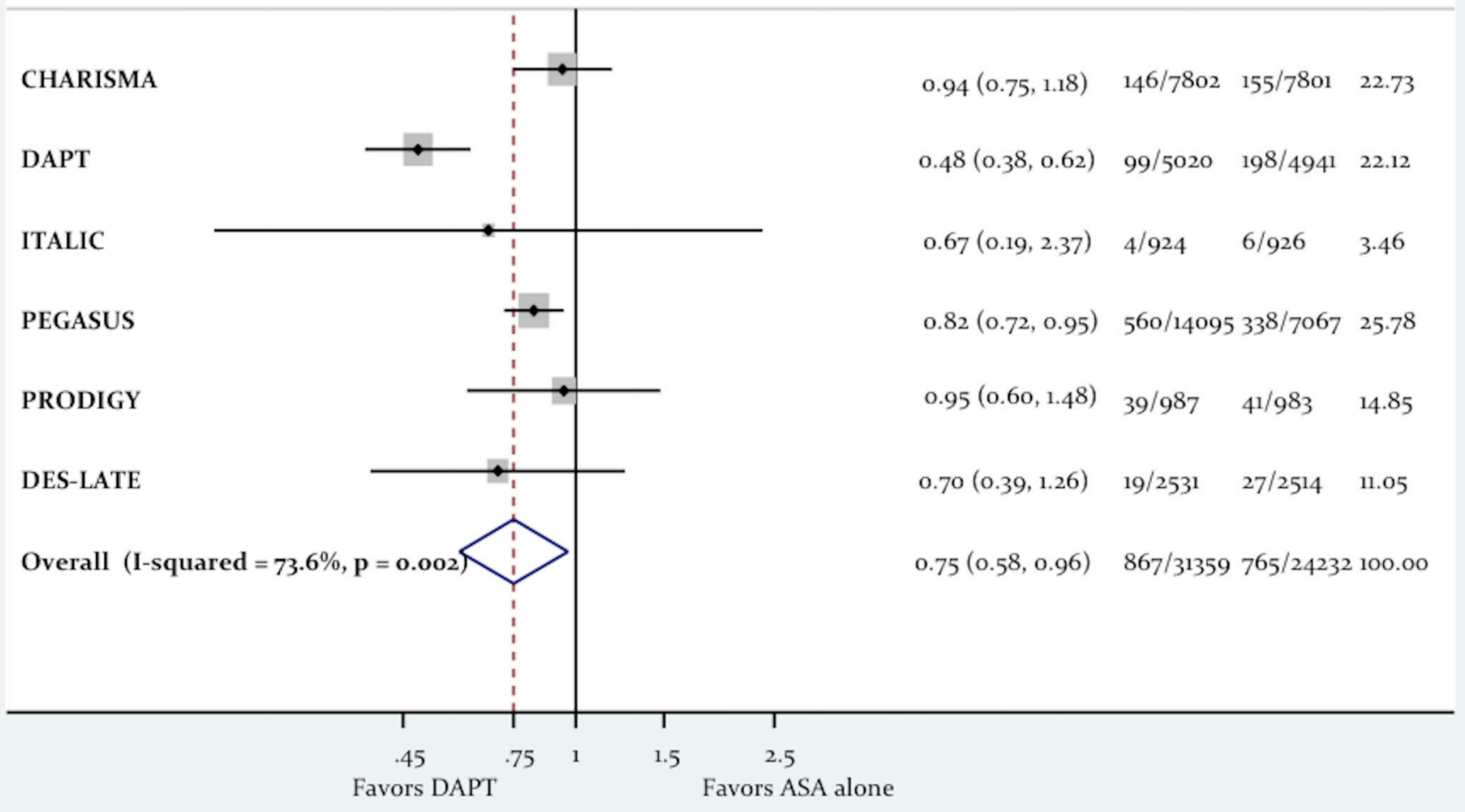




\section{DAPT vs. ASA alone: Stroke $(\mathrm{p}=\mathbf{0 . 0 7 4})$}

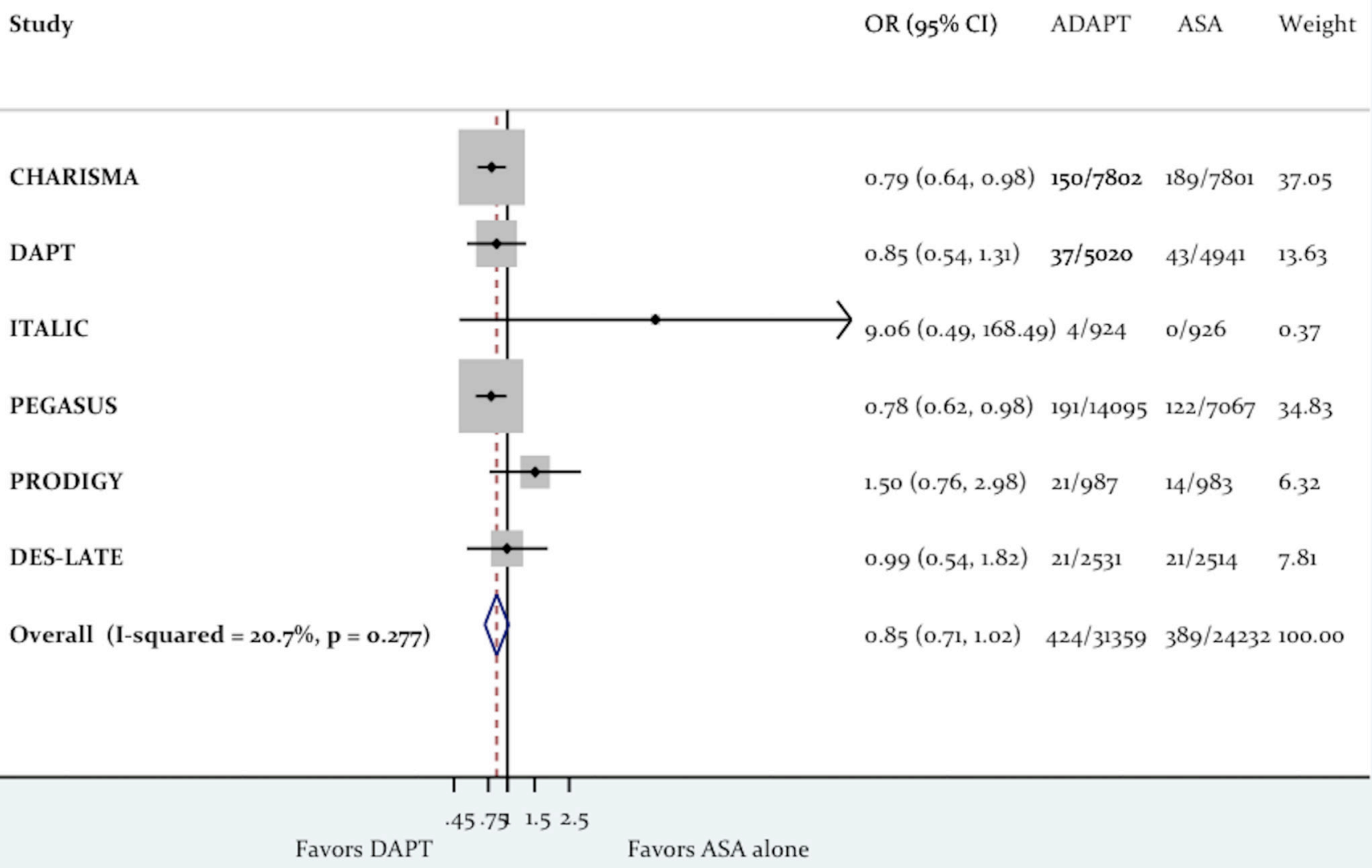

Figure-3.

The Impact Of Long Term DAPT On All-Cause Death, MI And Stroke. 


\section{DAPT vs. ASA alone: Minor-moderate bleeding $(\mathrm{p}<0.001)$}

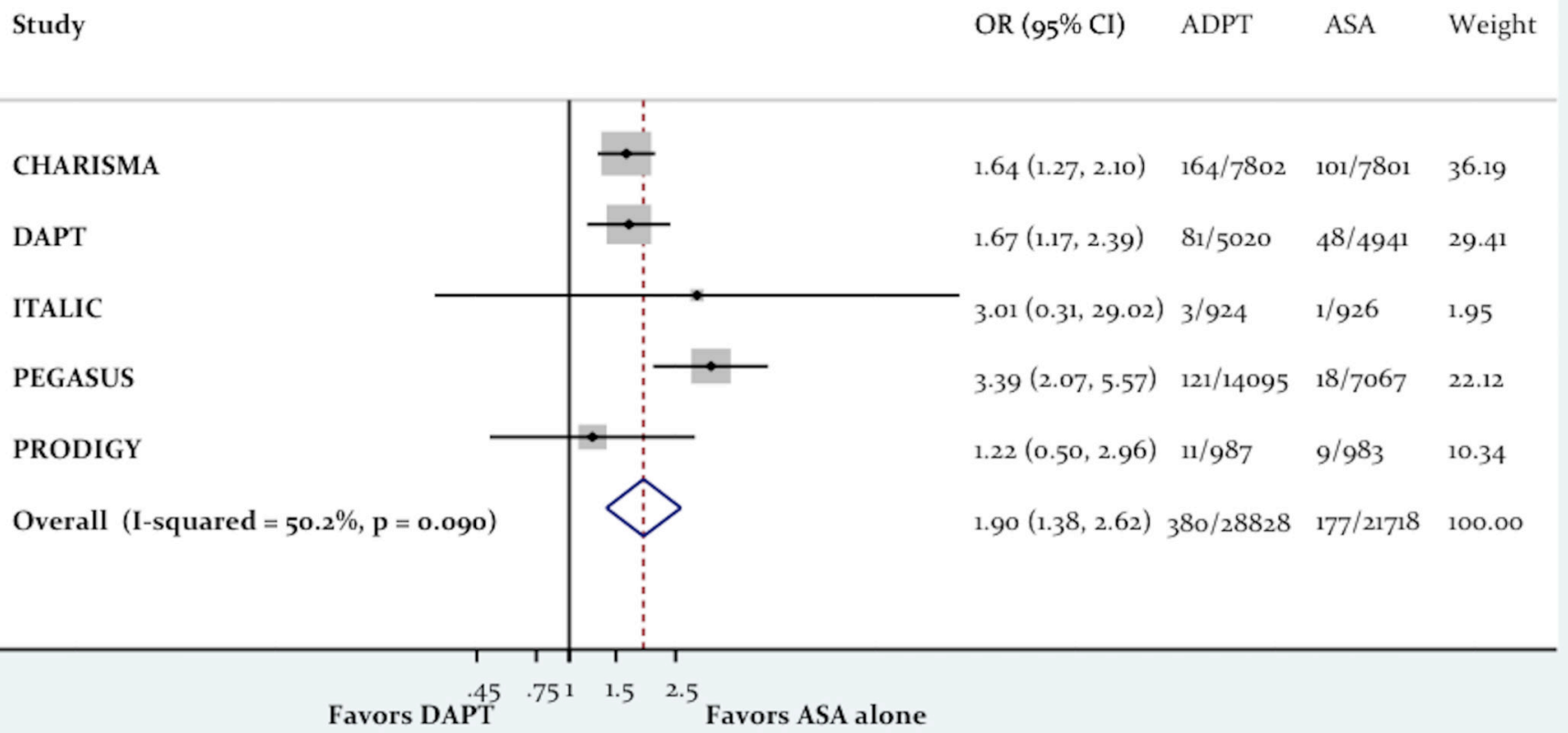

\section{DAPT vs. ASA alone: Major bleeding $(\mathrm{p}=\mathbf{0 . 0 0 1})$}

Study

\begin{tabular}{|c|c|c|c|c|c|}
\hline CHARISMA & $\rightarrow$ & $1.25(0.97,1.63)$ & $130 / 7802$ & $104 / 7801$ & 29.18 \\
\hline DAPT & & $1.44\left(0.87,2.3^{8}\right)$ & $38 / 5020$ & $26 / 4941$ & 17.98 \\
\hline ITALIC & & $3.01(0.12,73.98)$ & $1 / 924$ & $0 / 926$ & 0.82 \\
\hline PEGASUS & & $2.27(1.69,3.05)$ & $242 / 14095$ & $54 / 7067$ & 27.29 \\
\hline PRODIGY & & $2.68(1.05,6.89)$ & $16 / 987$ & $6 / 983$ & 7.69 \\
\hline DES-LATE & & $1.41(0.84,2.39)$ & $34 / 2531$ & $24 / 2514$ & 17.06 \\
\hline Overall $(\mathrm{I}$-squared $=52.3 \%, \mathrm{p}=0.063)$ & & $1.65(1.23,2.21)$ & $461 / 31359$ & $214 / 24232$ & 100.00 \\
\hline
\end{tabular}

Figure-4.

The Impact Of Long Term DAPT On Bleeding.
OR $(95 \% \mathrm{CI}) \quad$ ADPT $\quad$ ASA Weight 


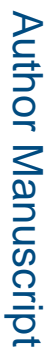

$\frac{\overline{0}}{\frac{0}{\sigma}}$

\begin{tabular}{|c|c|c|c|c|c|c|c|c|c|c|}
\hline A & \multicolumn{5}{|l|}{$\overrightarrow{\dot{\theta}}$} & & \multicolumn{4}{|l|}{ 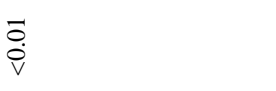 } \\
\hline$\sim \stackrel{\frac{\mathscr{\Xi}}{\pi}}{\frac{\pi}{\pi}}$ & \begin{tabular}{|l|} 
\\
$\vdots$ \\
$\vdots$ \\
0 \\
0
\end{tabular} & $\stackrel{\infty}{0}$ & $\stackrel{\overbrace{}}{\circ}$ & $\stackrel{\infty}{0}$ & $\stackrel{0}{a}$ & 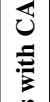 & $\stackrel{\infty}{0}$ & $\overrightarrow{\dot{a}}$ & $\begin{array}{l}\overline{8} \\
\dot{0} \\
\dot{v}\end{array}$ & $\overrightarrow{8}$ \\
\hline 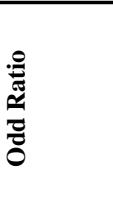 & $\begin{array}{l}7 \\
0 \\
0 \\
0 \\
\hat{0} \\
0 \\
0 \\
0 \\
0 \\
0\end{array}$ & $\begin{array}{l}F \\
F \\
0 \\
0 \\
0 \\
\infty \\
0 \\
\infty \\
\infty \\
0 \\
0\end{array}$ & $\begin{array}{l}\bar{\infty} \\
0 \\
0 \\
\vdots \\
0 \\
0 \\
\infty \\
\infty \\
0 \\
0\end{array}$ & 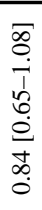 & 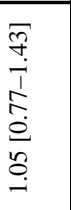 & 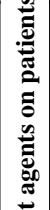 & 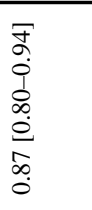 & 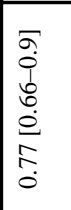 & 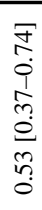 & 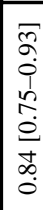 \\
\hline 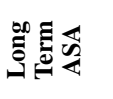 & $\begin{array}{l}\stackrel{0}{0} \\
\stackrel{2}{\sim} \\
\stackrel{1}{\sim}\end{array}$ & $\begin{array}{l}\stackrel{\infty}{0} \\
\dot{0} \\
\dot{b}\end{array}$ & $\begin{array}{l}0 \\
\stackrel{8}{0} \\
\stackrel{9}{0}\end{array}$ & $\begin{array}{l}\text { oे } \\
\text { के }\end{array}$ & 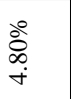 & 离 & 官 & 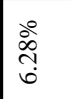 & $\begin{array}{l}\text { ¿̊ } \\
\text { in }\end{array}$ & 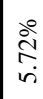 \\
\hline 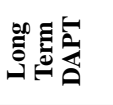 & 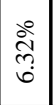 & $\begin{array}{l}\stackrel{8}{0} \\
\stackrel{+}{+}\end{array}$ & $\begin{array}{l}\stackrel{0}{\circ} \\
\dot{q} \\
\infty\end{array}$ & 옹 & $\begin{array}{l}\text { : } \\
\text { i̊ } \\
\text { in }\end{array}$ & 言 & $\begin{array}{l}\stackrel{0}{0} \\
\stackrel{0}{+} \\
\dot{+}\end{array}$ & $\begin{array}{l}\stackrel{\circ}{\circ} \\
\stackrel{\circ}{+} \\
\dot{+}\end{array}$ & $\frac{8}{\circ}$ & 总 \\
\hline 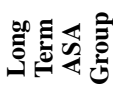 & 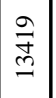 & 季 & $\stackrel{\vec{n}}{n}$ & $\stackrel{b}{*}$ & స్తి & 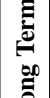 & గ్లి & 竎 & $\Xi$ & 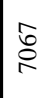 \\
\hline 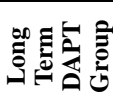 & 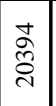 & 京 & $\begin{array}{l}\text { in } \\
\text { s } \\
\end{array}$ & $\frac{n}{i}$ & ڤે̊ & 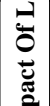 & ते & 亦 & $\stackrel{\text { g }}{\stackrel{\text { I }}{=}}$ & 告 \\
\hline 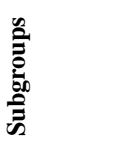 & 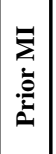 & 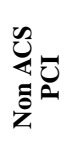 & 总 & बे & 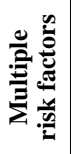 & 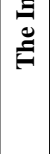 & 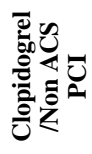 & 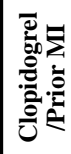 & 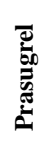 & 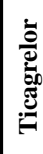 \\
\hline
\end{tabular}

Cardiovasc Revasc Med. Author manuscript; available in PMC 2018 January 01. 